\title{
La radio colombiana frente al reto digital
}

\section{The colombian radio in front of the digital challenge}

\author{
Andrés Barrios Rubio \\ Director Emisora Virtual Óyeme UJTML. Docente Asociado II, Universidad Jorge Tadeo Lozano, Bogotá, \\ Colombia. \\ andres.barrios@utadeo.edu.co
}

Resumen En casi 100 años de historia la radio colombiana ha hecho frente a diversos avances tecnológicos y movimientos sociales que la han llevado a reinventarse y adecuarse a las situaciones de la época. En este sentido la radio comercial, de interés público y comunitaria, hacen frente a la globalización del mundo y el impacto de las TIC en los medios de comunicación, abriendo paso al protagonismo de los oyentes y la convergencia de medios y plataformas, en un mercado que a través del ensayo y el error encuentra la estrategia de negocio que pasa de las ondas hertzianas a los diferentes aparatos de emisión y reproducción con que se cuenta.. A través de este estudio cuantitativo, que recurre al seguimiento de medios en sus emisiones y plataformas digitales, y cualitativo, que se aproxima a los actores del medio, se evidencia el estado de la radio colombiana frente al reto digital.

Abstrac In almost 100 years of Colombian radio has faced several technological and social movements that have led to reinvent itself and adapt to the situations of the time. Thus commercial radio, public and community interest facing the globalization of the world and the impact of ICT in the media making its way to prominence of the listeners and the convergence of media and platforms in a market that through trial and error is the business strategy of passing the various terrestrial broadcast and playback devices that are available in the market waves. Through this quantitative study, which uses monitoring media releases and digital platforms, and qualitative approaches to environmental actors, the state of the Colombian radio is evident in the digital challenge.

$\begin{array}{r}\text { Palabras } \\ \text { Clave }\end{array}$
Key
Words

- Agradecimientos: Esta investigación contó con el apoyo de la Universidad Jorge Tadeo Lozano, de Bogotá, Colombia, y la Universidad Autónoma de Barcelona, España. 


\section{La radio colombiana frente al reto digital}

El servicio de radiodifusión en Colombia se encuentra reglamentado a través de la Resolución 415 de 2010 del Ministerio de Tecnologías de la Información y las Comunicaciones, que establece el agrupamiento de emisoras en 3 tipos de estaciones acorde con las característica de su servicio: comercial, que hace referencia a estaciones con fines de lucro; Interés Público (Emisoras de la Radio Pública Nacional de Colombia, Emisoras de la Fuerza Pública, Emisoras Territoriales, Emisoras Educativas, Emisoras Educativas Universitarias y Emisoras para atención y prevención de desastres), donde se encuentran radios que buscan establecer un canal de comunicación entre el estado y la ciudadanía, al tiempo que cumplen con una labor educativa y cultural; y comunitaria, cuya finalidad es el encuentro entre las diferentes identidades sociales y expresiones culturales de una comunidad determinada.

A lo largo de su historia y desarrollo, 7 de agosto de 1929 a hoy, el servicio del medio radial se ha ido reinventando y adecuando a las características sociales de cada década, del mismo modo que ha ido evolucionando y asimilando cada una de las aportaciones tecnológicas del momento. El sismo más trascendental que ha debido afrontar es el adecuarse al entorno digital de las audiencias y el pasar de una comunicación unidireccional, eminentemente local, a afrontar la conformación de microredes de usuarios en un panorama global.

La sociedad de la información y el conocimiento abrió las puertas a nuevas formas de transmisión de contenido a través del uso y apropiación de las Tecnologías de la Información y de la Comunicación (TIC) que transformaron la vida del ser humano, de ser un receptor pasivo a convertirse en un usuario activo. La irrupción de estas tecnologías ligadas a la informática (ordenadores, dispositivos portátiles y redes de datos) ha abierto un nuevo espacio en que el periodismo y la comunicación se llevan a cabo en condiciones diferentes a las que permitían los medios convencionales.

El auge de esta revolución, con su eje central en el acceso, generación, procesamiento y transmisión de información; de los procesos creativos y artísticos, de los medios convencionales y la convergencia de estos con las plataformas digitales; de los modelos de propiedad de los massmedia y de las nuevas formas de comunicación masiva y personalizada que impulsan las industrias culturales, exigen un nuevo tipo de producción de mensajes basados en el conocimiento y la información como vectores de productividad, crecimiento económico y desarrollo social. 
Estos recursos tecnológicos implican gramáticas determinadas para la producción de medios, especialización en la oferta de contenidos, en su consumo, interacciones comunicativas y nuevas competencias y habilidades instrumentales por parte del periodista. Un panorama en que los medios deben hacer frente a tres exigencias que les plantea el entorno digital: una estrategia editorial para la producción constante y diversificada de contenidos, la renovación y actualización de procesos basados en los nuevos panoramas tecnológicos y comunicativos, y la apropiación y uso de las TIC (Salaverría, 2003).

Creadas las condiciones de una comunicación globalizada y globalizante, los medios de comunicación tradicionales han encontrado en Internet un medio que permite la coexistencia de todos los instrumentos técnicos y tecnológicos, y por ende, nuevas formas de llegar a sus destinatarios, de satisfacer las necesidades comunicativas, a la vez que se les demandan transformaciones importantes para amoldarse a sus características. Es decir, estas tecnologías de comunicación mediáticas y massmediáticas, poseen un nuevo medio, un nuevo canal que es Internet, el cual ha modificado por completo los procesos de recopilación, procesamiento, elaboración, difusión de la información, metodologías de análisis e incluso sus marcos conceptuales.

Los medios tradicionales se encuentran en un proceso de reinvención, migración y adaptación al entorno digital con que ofrecen a sus usuarios nuevas alternativas de consumo, al tiempo que generan simbiosis mediáticas en las que los profesionales de la comunicación se enfrentan a unos roles y labores que difieren de la especialización mediática tradicional que los obliga a adaptarse a lo que se conoce como cibermedios ${ }^{1}$ (Cebrián, 2009)

Analizar el fenómeno mediático colombiano en el mundo de hoy conlleva a tener presente los medios tradicionales como eje central de la mediación, así como aquella fusión y divergencia que trae consigo la digitalización de los medios y la convergencia de unos y otros. Se hace referencia a aquel escenario en el que cambia la difusión, uso y consumo, e interacción de los massmedia con los consumidores.

1 "Se entiende por «cibermedio » el proceso que va de un productor-emisor de contenidos y servicios informativos mediante estrategias y técnicas periodísticas específicas y adecuadas a las exigencias de la plataforma Internet y con la potencialidad incorporada por ésta como el uso integrado de varios sistemas expresivos: escrito, gráfico, icónico, auditivo, audiovisual y multimedia, hasta llegar a unos usuarios que pueden seguir, manejar o producir otras informaciones y entablar diálogo o intercambiarse los papeles con el emisor." (Cebrián, 2009:16) 
De la multimedia e interactividad, que impactó a la sociedad y los medios a inicio del siglo XXI, se pasó a la convergencia de los massmedia y la narrativa que ello implica. Un eje de diálogo que centra su accionar en la elaboración de productos comunicativos que requieren: el uso de más de un medio como soporte a las necesidades del tema o mensaje, el aprovechamiento de la potencialidad funcional y narrativa de cada medio, una producción integrada y posibilidades de accesibilidad desde distintos dispositivos (Scolari, 2013).

Los medios pasan por un proceso de convergencia empresarial, tecnológico, profesional y comunicativo en el que a través del ensayo y error se reinventan y reacomodan en un sistema narrativo que "inicia en las redes sociales, se expande en los portales web, la televisión, la radio y, el día siguiente, a los diarios impresos" (Scolari, 2013, p.120). Se habla de un espacio de convergencia en que cada medio se reinventa y potencia esa característica diferencial que tiene sobre el otro, es decir, se pasa por una etapa en la que el negocio no se acaba sino que se transforma y se adapta al entorno digital de las audiencias.

La convergencia, desde los medios, exige analizar el replanteamiento que propicia la tecnología en el quehacer propio de las radios convencionales. Se está en un momento en el que las emisoras integran las tecnologías a cada una de sus labores de modo que propician nuevas experiencias en sus productos comunicativos, a la vez que conforman redes de usuarios, aquellos que se identifican con la propuesta sonora de la estación radial.

Martínez (2009), reseña que la convergencia trae consigo una estrategia económica que habla de la concentración de medios en conglomerados empresariales que a través de la diversificación de productos y canales de difusión consolidan las audiencias y captan nuevos públicos. Es esa convergencia la que fortalece y proyecta lo que Jenkins (2003) llama narrativa transmedia, la capacidad que tiene el medio y sus comunicadores para proponer diversas rutas de ingreso a la información, un producto comunicativo que complementa lo expuesto en otro medio y permite al usuario reconstruir el contenido, compartirlo e interactuar a través de él con otros usuarios, el periodista y los massmedia.

La industria mediática está propiciando "un cambio cultural, ya que anima a los consumidores a buscar nueva información y a establecer conexiones entre contenidos mediáticos dispersos" (Jenkins, 2008, p.15). Una comunicación abierta a través de las redes sociales (Facebook, Twitter), comunidades (YouTube, Sound Cloud), blogs y foros, en la 
que unos y otros, sin importar la distancia, dan su punto de vista y construyen su vivencia y realidad percibida, dando origen a "una red comunicativa con la emisora y entre los usuarios que va más allá de la oferta de programación tradicional” (Cebrián, 2008, p.26).

La mediación entre el profesional, los hechos y el público está dada desde los cibermedios, espacios de comunicación que manejan un lenguaje comunicativo multimedia en el que a través del hipertexto se ofrece interactividad al usuario, se exploran nuevas narrativas en el desarrollo de los hechos y se proponen rutas de reconstrucción de la realidad. En esencia, la finalidad informativa de los cibermedios sigue siendo la misma, lo que varía es su producción y forma de llegar al usuario (Silva, 2013).

"El productor radiofónico actual y del futuro debe en consecuencia trabajar sobre dos modelos de comunicación: uno direccional, tradicional y local a través de la transmisión del sonido por aire; el segundo, bidireccional, dialógico, alternativo y global, por medio de los servicios interactivos aprovechables en la red" (Sosa, 2000, p.120). Desde los medios, se habla del replanteamiento de las dinámicas tradicionales de la prensa, la radio y la televisión no solo en su aspecto productivo, sino en la unificación de sus políticas editoriales y comerciales (Salaverría, 2010).

Las redes sociales obligaron a los medios de comunicación y a sus periodistas a evolucionar y buscar alternativas para innovar, de modo que involucran a la audiencia y la vuelven protagonista del esquema comunicativo. Se puede decir que han revolucionado la manera de crear, usar y distribuir contenido (Jaramillo, 2011). En tal sentido, Colombia atraviesa por un proceso de convergencia en que los medios se adecuan al entorno digital de las audiencias y a través de la experimentación se reinventan y acomodan al panorama mediático de un mundo globalizado que pide unir al medio convencional con las redes sociales, los portales web y los dispositivos digitales (Scolari, 2013).

Los medios colombianos pasan hoy por un acoplamiento con los medios digitales, un panorama en el que se producen modificaciones en la forma en que se percibe e interpreta el mundo por parte de los sujetos, en especial niños y jóvenes, llevando a un cambio progresivo de mentalidad en que el entorno tecnológico es el centro desde el cual se mira e interpreta la realidad (Pineda, 2012). La red se ha convertido en un lugar ideal para el consumo audiovisual y el encuentro entre personas, por ello los medios de comunicación empiezan a comprender que en el replanteamiento del entorno social, la información es la materia prima y la comunicación es el servicio (Lara, 2008). 
El proyecto que ahora se desarrolla centró la mirada en la integración de la radio colombiana y las nuevas tecnologías, un escenario en el que la palabra toma gran importancia y se convierte en el elemento clave a través del que se proponen contenidos y se redescubre la relación entre el medio y sus oyentes, para formar una audiencia más comprometida con una propuesta radial que involucra a más personas y a su vez gana más audiencia, más credibilidad y genera mecanismos de lealtad con la estación radial. Un proceso que implica comprender y dominar las estructuras de la literatura web, ese lenguaje transmedia, en que el audio, los videos, las imágenes, el texto, las etiquetas, entre otros, se combinan para construir textos llamativos que captan la atención de la audiencia en distintos escenarios.

\section{Metodología}

Teniendo presente que los resultados del $\mathrm{ECAR}^{2}$ muestran el fuerte impacto del medio radial y su incidencia en los diferentes frentes de la sociedad, el cómo las empresas radiales generan propuestas para cada uno de los públicos con un objetivo determinado, que brinda una visión del acontecer diario y permite la construcción de narrativas particulares; se determinó tomar como objeto de estudio a la principal emisora comercial colombiana (Caracol), la estación radial de Interés Público del Estado (Señal Radio Colombia), y una radio Comunitaria con fuerte reconocimiento en la capital colombiana (Suba Al Aire).

El estudio que ahora se referencia empleó una metodología cualitativa (entrevistas semiestructuradas a profundidad, análisis páginas web) y cuantitativa (análisis de contenido y seguimiento a redes sociales). El método implementado tuvo un carácter: Investigativo, dado que se hizo una revisión bibliográfica para determinar la relación, uso, o influencia de las redes sociales en el diseño y funcionamiento de emisoras radiales en Colombia. De campo, debido a que se hicieron recorridos virtuales (mediante el uso de redes sociales, páginas web) y presenciales en los cuales se aplicaron entrevistas para realizar un diagnóstico del estado actual de la radio que guiara o diera el insumo básico de trabajo de la siguiente fase (analítica). Analítico, dado que con la información obtenida en las fases investigativa y de campo se efectuó un diagnóstico del estado actual de la radio en Colombia en un proceso de convergencia.

Para este análisis realizado durante el cuarto trimestre de 2014, se recurrió a los planteamientos metodológicos expuestos por Peña (2012) que proponen determinar

2 Estudio Continuo de Audiencia Radial que es realizado por el Centro Nacional de Consultoría, en 3 olas de 4 meses cada una al año. 
cómo los medios convencionales se abren a la participación de los oyentes en sus contenidos tradicionales, el traslado de los contenidos emitidos por el medio tradicional a la Red, y el cómo la voz de los oyentes en las redes sociales es trasladada a la antena de manera que se nutren y fortalecen los contenidos del medio, para este caso la radio convencional.

Para la recolección del material sonoro se recurrió a la muestra de semana compuesta propuesto por Gutiérrez (2014). El establecimiento de los datos cuantitativos fue realizado mediante la aplicación de instrumentos que fueron validados antes de su aplicación acorde a lo expuesto por Wimmer \& Dominick (1996), lo que dio certeza a la unificación de conceptos y la validación de cada una de las categorías de análisis.

Recolectados y cuantificados los datos del seguimiento se procedió a entrar en contacto con los actores de dichas emisoras para abordar una entrevista semiestructurada, constituida por preguntas abiertas y flexibles, en la que se tenía por objetivo establecer: la influencia de las redes sociales en el quehacer de la radio, la preparación que tienen para afrontar los desafíos del entorno digital, y la respuesta a las necesidades de un público digital y globalizado.

Se buscó con esta metodología analizar, a través de las entrevistas, el planteamiento de los actores de la radio en Colombia, encontrando sus diferentes niveles de significación, que dan cuenta de las diversas formas que tiene éste para la construcción de la noción de realidad. El eje metodológico fundamental es el análisis discursivo (Londoño \& Frias, 2011).

Haciendo uso de la herramienta Twitonomy, http://www.twitonomy.com, se revisaron los últimos 3200 tweets, de las emisoras objeto de estudio, desde donde extraemos nuestros resultados. 


\section{Resultados}

Tabla 1 / Estadisticas Twitter

\begin{tabular}{|c|c|c|c|}
\hline MEDIO /CARACTERÍSTICA & CARACOL RADIO & SEÑAL RADIO COLOMBIA & SUBA AL AIRE \\
\hline Seguidores & 1.725 .658 & 128.191 & 3.126 \\
\hline Promedio twittes por día & 94 & 100 & 14 \\
\hline RT realizados por la cuenta & 301 & 445 & 2281 \\
\hline Usuarios mencionados & 350 & 1.962 & 608 \\
\hline Respuestas brindadas & 1 & 9 & 31 \\
\hline Hipervínculos insertados & 2.854 & 1.567 & 723 \\
\hline Hashtags & 888 & 3.020 & 639 \\
\hline Twittes que recibieron RT & 2.714 & 1.835 & 155 \\
\hline $\begin{array}{l}\text { RT que recibieron los men- } \\
\text { sajes emitidos por el medio }\end{array}$ & 24.007 & 5.166 & 207 \\
\hline $\begin{array}{l}\text { Twittes que recibieron } \\
\text { "Favorito" }\end{array}$ & 2.691 & 1.725 & 107 \\
\hline $\begin{array}{l}\text { "Favorito" que recibieron los } \\
\text { mensajes emitidos por } \\
\text { el medio }\end{array}$ & 17.519 & 4.236 & 131 \\
\hline
\end{tabular}

Fuente: Elaboración Propia con los datos de Twitonomy

Para revisar las cuentas de las emisoras en Facebook se empleó la plataforma Likealyzer, http://likealyzer.com, de la que se infieren los siguientes datos:

Tabla 2 Estadísticas Facebook

\begin{tabular}{|l|c|c|c|}
\hline MEDIO / CARACTERÍSTICA & CARACOL RADIO & SEÑAL RADIO COLOMBIA & SUBA AL AIRE \\
\hline \begin{tabular}{l} 
Seguidores \\
\hline Publicaciones por día
\end{tabular} & 268.410 & 52.563 & 7.090 \\
\hline $\begin{array}{l}\text { Me Gusta, comentarios y } \\
\text { acciones por post }\end{array}$ & 115 & 4 & 3 \\
\hline
\end{tabular}

Fuente: Elaboración Propia con los datos de Likealyzer 
Se puede afirmar que en el campo digital existen tremendas coincidencias, pero también profundas diferencias entre la radio comercial, de interés público y comunitaria en Colombia. Cada una responde en sus planes y acciones en el campo digital al objeto de la concesión, pues en la primera se destacan los fines lucrativos y de marca que se desarrollan, en la segunda la labor informativa, educativa y formativa por parte del Estado, y en la tercera el esfuerzo de una comunidad por tener una voz en las ondas hertzianas y el campo digital.

En el diseño de páginas web, las emisoras objeto de estudio responden a las características de su medio y el tipo de radio que representan:

- http://www.caracol.com.co Como medio comercial informativo con 60 años de tradición en el mercado radial colombiano responde a la formalidad y seriedad de la noticia. Se aprecian titulares cortos y atrayentes que respaldan su objetivo comunicativo con fotografías y entradillas fuertes y que hablan por sí solos e invitan a seguir la información.

Se encuentra la autopromoción del programa que está al aire y su realizador, importantes espacios de la página dedicados a la publicidad, vínculos fuertes con los portales deportivos de la emisora, y una atractiva promoción de los audios más destacados de la programación diaria, así como las entrevistas realizadas.

- http://www.senalradiocolombia.gov.co El sistema de medios públicos de Colombia ofrece a los usuarios, respondiendo a la apuesta del Ministerio de Tecnologías de la Información y las Comunicaciones, un portal que incorpora una imagen actual y de tecnología de punta. Responde a las necesidades informativas del Estado con sus ciudadanos, rescatando los valores y la cultura nacional, para ello se apoya de los banner en la página inicial y la distribución de hechos por secciones.

Se auto promociona directamente el espacio que está en vivo y sus realizadores, así mismo, los temas más relevantes por ser los más leídos y compartidos desde la página y las redes sociales. Dedica un espacio de impacto y concede fuerte importancia a los Podcast.

Como elementos comunes en el medio comercial y de interés público se encuentran: los principales datos informativos de la economía, el clima, el tráfico, los vínculos con otros medios del grupo, blogs de los periodistas y menús que permiten el fácil desplazamiento al interior de las páginas. 
- http://subaalaire.com En su blog, que funge como página web, se aprecia que al tratarse de un medio comunitario no puede ocultar las limitaciones de contar con bajos recursos económicos para el ejercicio de su actividad comercial. De lo anterior, se comprende una página básica que trata de proyectar modernismo e interactividad, pero sus vínculos no conducen a nada o pasan a una página en construcción.

Es evidente la intención de ofrecer contenidos atractivos, pero las cajas dispuestas para tal fin son más grandes que la información desarrollada. Se debe destacar que es la única de las páginas que ofrece vínculo directo a las redes sociales y apuesta por un chat de diálogo en vivo.

En las entrevistas realizadas a Diana Calderón, Directora del Sistema Informativo de Caracol Radio; Julián Andrés Bohórquez, Coordinador de Proyectos de Señal Radio Colombia; y Heber Cuadrado Rodríguez, Director de la Emisora Suba Al Aire; se tocaron tópicos de las redes sociales, la radio en el entorno digital, la audiencia en el panorama mediático del mundo de hoy y la relación del medio-audiencia-campo digital.

Del diálogo se extraen las expresiones más comunes al hacer referencia al tema de consulta y la forma de visualizar cada emisora su presencia en el espacio digital, como mecanismo de integración e interacción con la audiencia.

Gráfico 1: Los actores de radio y sus expresiones recurrentes al hacer referencia al medio en el entorno digital

Fuente: Elaboración Propia

\section{Redes Sociales - Radio en el entorno digital.}

Espacio de estrategias

\begin{abstract}
Vías de acceso al medio.
\end{abstract}

Área de visibilidad y Propagación

\begin{tabular}{c|c} 
Canal de & Plataforma \\
comunicación & complementaria
\end{tabular}

\begin{abstract}
Acceso a potenciales oyentes.
\end{abstract}

\section{El público, el entorno digital y la radio.}


Es evidente que se está en un entorno en el que los medios de comunicación establecen estrategias bajo las cuales incorporan a los oyentes en su producto comunicativo, para ello recurren a la visualización de aquello que sale al aire y visibilizan a sus protagonistas. La Red es un canal de comunicación que se constituyó en la plataforma complementaria que da acceso no solo a la audiencia cautiva, sino a los potenciales oyentes de la propuesta sonora del medio.

Este es un momento de reinvención del medio y su relación con el público bajo el escenario digital, ello implica el establecer unas estrategias de identidad que desde la creatividad responda a las expectativas del público y establezca una afinidad que fortalezca la conformación de redes. Se habla de un esquema de producción que inicia en el medio, pasa a Twitter, continúa en Facebook y finaliza en la web; una narrativa que permite al usuario explorar en diversos escenarios y encontrar pistas que lo conducen al portal y la propuesta comunicativa del medio.

\section{Discusión}

La radio comercial en el marco de un boom tecnológico que se toma las salas de emisión, pero también las salas de producción y las salas de redacción está replanteando los actores del proceso comunicativo, así como las labores funcionales de los periodistas. Hoy en la radio ya no priman las voces bellas sino aquella persona que tenga las competencias para realizar un registro noticioso, al tiempo que se apersona, aún más, de los contenidos con un concepto y pensamiento digital que le permiten configurar mensajes de tal manera que la radio llega a los usuarios por unos canales que no son simplemente los de los aparatos reproductores tradicionales.

El medio comienza a dar un giro en su concepción y forma de actuar, pues la de hoy es una radio que busca la interactividad, de ahí que a través de las redes sociales luche por contar con miles de reporteros volantes gratuitos que están registrando aquello que ven. Atrás quedó ese massmedia que estructuraba productos en una sola vía, en los que la radio decía lo que estaba pasando y el consumidor se informaba.

Con la aparición de los nuevos medios, internet, las aplicaciones del celular, la inmediatez de la televisión, la información no pasa a un segundo plano, pero simplemente pasa a ser una de las esquinas de la mesa de la radio. La gente busca entretenimiento, alguna manera de educarse, pero sobre todo participar, que es lo que sucede con los medios de 
comunicación que así lo permiten, de ahí que el vínculo radio, internet y redes sociales sea tan importante.

La labor de la radio pública está encaminada a los núcleos poblacionales de las regiones colombianas, de ahí que se aprecie una clara estrategia de llegar al campo y las poblaciones más apartadas del país con una propuesta sonora que no recurre a las estrategias digitales, las cuales están encaminadas a fortalecer ese vínculo con los receptores de las grandes capitales del País. La idea es trasladar al campo digital esos acentos y la voz de los colombianos con la ayuda de la música, los sonidos, la poesía y las historias.

Para el Sistema de Medios Públicos en Colombia existe una preocupación latente por brindar a los ciudadanos diversas alternativas de participación y en las redes sociales tienen un canal directo con el que los colombianos, dentro y fuera de las fronteras nacionales, tienen la capacidad de participar al aire, de expresarse, ser escuchado, ser oído y al mismo tiempo de encontrar un servicio que va más allá de una ayuda, una guía, pues la inquietud se transfiere al Ministerio, a la entidad o la persona encargada de dar respuesta al ciudadano.

Es una participación que no solo se lleva al campo de la queja, incluye también la solicitud de un disco, un tema al aire, la participación en un programa de servicio, así como intervenciones en temas culturales. Son canales que dan voz al oyente y se ven evidenciados en la programación, en la parrilla de Señal Radio Colombia.

Al igual que lo hace la radio comercial, la radio pública está creando plataformas para que los oyentes no solamente puedan escucharlos sino que tengan la posibilidad también de verlos y vivirlos. Ello va acompañado de una serie de elementos en los que a través de la página web se comparten videos, se desarrollan noticias, se proponen temas y se promocionan y llevan a cabo eventos. Elementos que encuentran difusión bajo unas estrategias de comunicación en redes sociales, y abren nuevos canales de emisión que buscan satisfacer las necesidades del oyente.

Una ventaja que tiene el Sistema de Medios Públicos, sobre las emisoras comerciales y las comunitarias, es contar con la memoria sonora del País a través de senalmemoria.gov.co donde se encuentran los principales discursos, los slogans y mejores programas de la radio nacional, y aquellos hechos que construyen la historia de Colombia a partir de los sonidos. Elementos que los oyentes no solamente encuentran a través de la web sino que llegan a ellos a través de diversas plataformas digitales, teléfonos inteligentes y el sistema US. 
La radio comunitaria desde sus limitaciones busca ponerse a tono con las propuestas digitales de la radio comercial y la radio de interés público, pero dado lo precario de sus recursos económicos y el bajo personal de base con que cuenta para sus acciones diarias, sus blogs informativos carecen de actualización constante. Los recursos gráficos y visuales son básicos, pero poco explotados en las narrativas del mundo digital.

No se puede desconocer un esfuerzo, por parte de la radio comunitaria, de llevar a la red una estrategia comunicativa que permita reconocer las manifestaciones culturales y sociales de un núcleo determinado de la población. Una alternativa para construir una propuesta sonora y mediática que, desde las manos de una sociedad legalmente constituida, logra superar los intereses económicos, sociales, políticos y culturales de los grandes conglomerados.

Las TIC modificaron la forma de consumir el producto radiofónico, el oyente hoy no solo está en el dial. Twitter se convierte en un mecanismo útil que facilita tener acceso a los oyentes para enriquecer la radio, saber qué piensa la gente de primera mano, lo importante está en establecer diálogos y dejarse nutrir del usuario. Al plantear preguntas al aire los receptores responden de inmediato, buscan una mención en la señal al aire o un retweet lo cual agradecen mucho porque es el reconocimiento a un contenido realmente valioso, diferente, divertido o creativo a través de las redes sociales.

Las redes sociales son ese mecanismo por excelencia que se ha inventado el ser humano para que la gente pueda participar, para que todos puedan opinar, para que todos tengan sus quince segundos de fama. Un espacio virtual en el que los periodistas y locutores se bajan del pedestal, de la tarima desde la que son generadores de opinión, para ponerse en el mismo nivel e interactuar con el oyente. Las redes sociales propician un esquema comunicativo de gran importancia en el que el receptor cobra protagonismo e impone temas en el ambiente social; un espacio virtual, en que todos establecen unas microredes de acción e interacción y dicen ejercer el servicio del periodismo básico en 140 caracteres.

Las redes sociales se convierten en igualadoras sociales que responden a la velocidad de las necesidades del mundo de hoy, en donde todos quieren tener los mismos derechos y capacidad de expresión. En tal sentido, la radio comprende que debe estar presente en Facebook y Twitter, pues en ellas establece con sus seguidores un punto de encuentro en 
el que a través de lo digital los receptores hablan en tiempo real; un lugar común en que se establece una red de complicidad, agregación, conversación y amistad entre unos y otros.

La generación de contenidos y el establecimiento de la agenda radial han cambiado con la tecnología, antes se trabajaba con intuición, con lo que se percibía podía ser el tema, lo que se creía podía interesar a los grupos poblacionales sujetos de la información. Hoy en un mundo híper-conectado es fundamental constatar lo que se dice en el ágora mundial que es Twitter, para de este modo estructurar los temas de una manera diferente, más amena, más agradable, más contextualizada, más completa, haciendo uso de un lenguaje generalista que satisfaga a todo el público.

Hace algunos años se hablaba de la agenda setting y se decía que eran los medios quienes establecían la agenda ciudadana y los temas de relevancia; hoy las cosas son al contrario, son las personas las que a través de las redes sociales, con sus tendencias, los trendingtopic, establecen la ruta a seguir en el desarrollo de los programas radiales.

El poder de Twitter sobre los contenidos de los medios radica en el contacto directo que tiene la gente con los periodistas, con los que hacen la radio, porque dan cuenta de muchas cosas, piden contenidos, sugieren temáticas y llaman la atención del periodista de modo que hay una respuesta y se convierte en algo notablemente interactivo; pero, si se mira de dónde sale la agenda que circula en la red social se encontrará qué es lo que está pasando en los medios, lo que se discute en la radio. De lo anterior, se desprende que los massmedia son quienes imponen la agenda noticiosa, y la agenda sobre los temas triviales, graciosos, de injusticia, los impone la gente, de modo que cuando cobran fuerza hacen parte de un noticiero de televisión, de radio, de un programa de farándula o un programa de variedades. Bajo ese precepto la red maneja los temas que agenda el medio de comunicación.

Se puede decir que los medios tienen una estrategia particular de redes sociales en la que quince días antes de un evento empiezan a lanzar, no solo al aire, sino en redes sociales un mensaje cada tres horas, "el próximo 8 de noviembre Señal Radio Colombia estará...". Ocho días antes, empieza un trino por hora, lo cual va acompañado de una nota en la página web y de una estrategia al aire que busca que la gente conozca y entienda qué se está haciendo, y cómo se está haciendo. Faltando tres días, se intensifica la acción llegando a tres trinos por hora, de modo que se ataca a todos los públicos en las diversas horas del día. Esto porque entienden que finalmente hoy, la radio, los medios de comunicación y la gente, se mueven a través de teléfonos inteligentes. 
Es claro que la tecnología acaparó el mercado y rápidamente los periodistas y los medios de comunicación percibieron que era necesario aliarse a ella, entrar a una era de digitalización en la que se debe responder a la generación de productos multimedia y se especializan los periodistas en los nuevos lenguajes, para combinar el trabajo convencional con el del campo digital en el que los comunicadores aparecen en las redes sociales, viven con los correos de los oyentes, publican sus post, hacen columnas digitales, hacen blogs, y aparecen allí, inmersos en el campo digital.

Poco a poco los medios radiales comprenden que deben incorporar a sus propuestas comunicativas el video y el texto que complementan su herramienta fundamental de trabajo que es el sonido. Se habla de un "mestizaje" entre radio tradicional y radio en la red en el que adquiere relevancia el Podcast; ese elemento que es un complemento del espacio radial, una continuación de la propuesta sonora que se hizo al aire, un microprograma de 7 o 10 minutos con una opinión guiada, un programa diferente o quizás paralelo a aquello que salió al aire, más no es igual.

Se evidencia que a la radio le hace falta rejuvenecerse en varios aspectos, se debe crear una verdadera estrategia comunicativa en el campo digital y explotar los recursos que ofrece el mundo tecnológico de hoy. Las páginas web de las emisoras no son solo para hacer publicidad, deben ser canales de distribución, el lugar donde se ubican las propuestas de la radio convencional, pero al tiempo se generan nuevas propuestas sonoras para nichos de público específico.

\section{Conclusiones}

Para el público las emisoras comerciales son la radio bonita, con plata, el medio de los slogans, el massmedia hermoso, maravilloso, perfecto, en el que todos quieren trabajar. La radio pública es vista como aquel medio aburrido, al cual da pereza escuchar, ese espacio sonoro que no aporta y da pena, sin entender que el Sistema de Medios Públicos es más que simple información, análisis y educación. Por su parte, la radio comunitaria es asumida como un espacio de práctica en el que la ciudadanía explora el quehacer de un medio de comunicación y es una alternativa para escuchar en algún momento del día.

La radio colombiana, en sus diversas características de servicio, está comenzando a trabajar para la audiencia digital, está pensando en crear convergencia con los canales de televisión, piensa en multimedia y utiliza la página web y las redes sociales como forma 
de acercamiento y visualización de las emisoras porque tienen la firme creencia de que la radio no solo se oye, también se ve.

Mientras, en la radio comercial existe una lucha entre las estaciones y los periodistas por ligar las cuentas personales de los actores del medio a la marca de la emisora y no dejar una marca personal por encima del producto radiofónico, en la radio pública se tiene claro que lo que hay que potenciar es la marca de la emisora y que los periodistas son parte de esa marca. Se cree que se debe consolidar ante los oyentes un profesional de las comunicaciones que responde a los requerimientos del entorno multimediático. La apuesta en redes sociales se convierte en no dar información por dar información, sino que los hechos sean analizados y vistos desde todos los puntos que lo afectan.

Se puede afirmar que en este proceso de digitalización y de competencia de medios, la radio comunitaria está quedada frente a la comercial y la pública por ser un nicho tan cerrado. Las propuestas sonoras comunitarias no reciben ningún tipo de apoyo, en un número elevado de casos, este tipo de radios son iniciativas particulares que inician con mucho impulso y amor por el medio, pero al poco tiempo se enfrenta a un mercado en el que buscan salir adelante con las uñas, sin tener mayores triunfos.

Se puede afirmar que los medios de comunicación tradicionales y los profesionales de la comunicación se encuentran ante uno de los mayores desafíos, causado por la evolución tecnológica. Estos avances han permitido que surjan nuevos medios y nuevos dispositivos, lo que significa que se están creando nuevos escenarios que platean un reto no solo para los medios periodísticos, sino para los periodistas que deben plantear y experimentar nuevas formas de informar y comunicar.

Esta es una etapa en la que la relación entre la radio y sus oyentes se ha vuelto mucho más abierta, franca y de confianza, de absoluto respeto por la autonomía, por el derecho a la información, a la libertad de expresión y el respeto a la defensa del régimen democrático. Se habla de una radio participativa donde se tiene en cuenta a todo el mundo; una radio con roles definidos en las mesas de trabajo. Lo que ha cambiado de fondo son las plataformas, la inmediatez, la calidad del sonido, la posibilidad de comunicarse con la gente en un segundo, el transmitir y el recibir información más ampliamente con mayor cobertura en muchas más partes del mundo al mismo tiempo. 
Los medios de comunicación tradicionales han disminuido su influencia en las audiencias. La capacidad de informar ya no les pertenece sólo a ellos, por el contrario, hoy el ecosistema mediático es un complejo escenario formado por periodistas, usuarios y máquinas, que con distintos lenguajes y formas de narrar, crean e intercambian contenidos en plataformas digitales.

El panorama acá reflejado fija un reto para las Universidades y por ende para la radio universitaria, porque de nada sirve un buen trabajo o una buena acción estratégica de la radio si la academia no lo involucra, no inculca a los estudiantes una buena radio. Hoy, la academia debe estar pensando más en crear mejores oyentes que mejores locutores, porque el que sabe oír sabe hablar y de nada sirve escuchar programas que no aportan absolutamente nada y que los jóvenes siguen escuchando sencillamente por moda. Hay que tener un criterio y ahí la academia tiene que jugar un papel importante y hacerle entender a los jóvenes que la radio no es hablar por hablar, que hacer un programa de radio es una meta, que implica unos objetivos claros con plan de crecimiento. Un espacio de radio debe ser algo que deje huella.

El error está en creer que la radio debe ser diferente cuando el medio debe ser uno solo, es decir, una emisora que contenga absolutamente todo, una propuesta sonora que eduque, forme, acompañe, lidere, guie, preste un servicio, pero que al mismo tiempo esté en capacidad de ser auto sostenible. Hay que cambiar mucho el concepto de lo que es la radio comercial, de interés público y comunitaria; en otros países del mundo todas compiten en igualdad de condiciones y adoptan lo propio de su cultura para apropiarlo y generar pertenencia frente a ello. En Colombia se prefiere asumir los valores de otras culturas, antes que asumir los propios a través de un medio de comunicación como es la radio.

La redes sociales se posicionan como una herramienta valiosa en la construcción de estrategias que contribuyan a mejorar indicadores de éxito asociados a una emisora (rating, penetración de mercado, frecuencia de audición, entre otros), debido a que se puede captar con relativa facilidad y rapidez la percepción de los usuarios, sus preferencias, sus gustos, sus opiniones, y otro tipo de información, que permite responder o reaccionar a dichos datos con el diseño e implementación de acciones estratégicas.

La utilización de redes sociales para la elaboración o construcción de un producto radiofónico toma cada día mayor importancia, debido a que las grandes masas de personas 
que integran dichas redes permiten la obtención y distribución de una importante cantidad de información en tiempo real, la pluralidad de fuentes de información, la difusión masiva, entre otros.

No se puede desconocer que el éxito en la onda hertziana y en el campo digital radica en el análisis que se realice a los datos de los interesados recopilados de las distintas fuentes de información, debido a que en esta se encontrarán los gustos, requerimientos, opiniones, deseos, expectativas, u otro tipo de información, que indique cuál es la preferencia del usuario hacia este tipo de medios de comunicación.

El campo tecnológico ha simplificado procesos y replanteado el accionar de la radio, y sería errado el calificarlo como positivo o negativo. El medio, al igual que lo ha realizado a lo largo de su historia, debe explotar su capacidad de planeación, gestión, medición, control y organización para diversificar el negocio y potenciar su característica principal, el sonido, de modo que se siga llevando la señal por las ondas hertzianas y se propaguen con la tecnología por los megabytes.

Referencias Cebrián, M. (2009). Comunicación interactiva en los cibermedios. Comunicar. Vol. 17 Núm. 33 Pp. 1524. doi: 10.3916/c33-2009-02-001

Cebrián, M. (2008). La radio en Internet. De la ciberradio a las redes sociales y a la radio móvil. Buenos Aires: La Crujía.

Centro Nacional de Consultoría (2013). Estudio Continuo de Audiencia Radial ECAR 2013-3. Bogotá - Colombia.

Gutiérrez, M.; Martí, J. M.; Ferrer, l.; Monclús, B.; Ribes, X. (2014). Los programas radiofónicos españoles de prime time en Facebook y Twitter: Sinergias entre la radio convencional y las redes sociales. Revista Latina de Comunicación Social. 69, 418-434. doi: 10.4185/RLCS-2014-1018

Jaramillo, A. M. (2011). Redes sociales para todos, su negocio en la web 2.0. Bogotá: Ediciones B.

Jenkins, H. (2008). Convergence cultura. La Cultura de la convergencia de los medios de comunicación. Barcelona: Paidos.

Jenkins, H.(2003). Transmedia Storytelling. Moving characters from books to films to video games can make them stronger and more compelling. Technology Review. Disponible en http://www. technologyreview.com/biotech/13052/7

Lara T. (2008) La nueva esfera pública. Los medios de comunicación como redes sociales en Telos Cuadernos de Comunicación e Innovación. Disponible en http://sociedadinformacion.fundacion. telefonica.com/telos/articulocuaderno.asp@idarticulo=9\&rev=76.htm 
Londoño, D. A. y Frías, L. Y. (2011). Análisis crítico del discurso y arqueología del saber: dos opciones de estudio de la sociedad. Revista Palabra Clave. No. 1. Vol. 14. Pág. 101-121.

Pineda, M. (2012). Nuevas aproximaciones teóricas de la comunicación en un entorno posmoderno. Disponible en: http://portalcomunicacion.com/lecciones_det.asp?lng=esp\&id=66

Martínez, J. (2009). La convergencia mediática: definición y perspectivas. En Relaciones públicas en Puerto Rico. Colegio Nacional de Periodistas DC Caracas. Disponible en http://cnpcaracas. org/2009/03/tendencias/la-convergencia-mediatica-definicion-y-perspectivas/

Ministerio de Tecnologías de la Información y las Comunicaciones. (2010). Resolución 415 de 2010, "Por la cual se expide el Reglamento de Radiodifusión Sonora y se dictan otras disposiciones".

Peña, P. (2012). Nuevas formas de participación: interactividad y redes sociales en la radio española. Revista Telos (Cuadernos de Comunicación e Innovación). Vol. 1. Pp. 1-13.

Salaverría, R. (2010). Convergencia Digital. En Xosé López y Xosé Pereita (eds.) (2010). Reconfiguración de los medios de comunicación en España. Pp. 27-40. Santiago de Compostela: Servicio Editorial de la Universidad de Santiago de Compostela.

Salaverría, R. (2003). Convergencia de los medios. Revista Latinoamericana de Comunicación, Chasqui. Núm. 081. Pp. 32-39.

Scolari, C. (2013) Narrativas Transmedia. Madrid - España: Editorial Grupo Planeta.

Silva, A. (2013): Los cibermedios y los móviles: una relación de desconfianza. Icono 14. Vol. 11 (2). Pp. 183- 207.

Sosa G. (2000). Radio e internet: la inevitable convergencia tecnológica. En Islas, O. (Coord.) Internet: el medio inteligente. México: Editorial Patria. Pág. 112-123.

Wimmer, R. y Dominick, J. (1996). La investigación científica de los medios de comunicación. Una introducción a sus métodos. Barcelona: Bosch. 